\title{
THE EFFECTIVENESSOFEARLYCUNICALEXPOSUREANDE-LEARNING IN
} TEACHING ANATOMY

\section{Chimmalgi M ${ }^{* 1}$, Regi Jose ${ }^{2}, \mathrm{~K}$ Chandra Kumari ${ }^{1}$.}

${ }^{* 1}$ Professor of Anatomy, Sree Gokulam Medical College $\&$ Research Foundation, Venjaramoodu, Trivandrum, Kerala, India.

2 Professor of Community Medicine, Sree Gokulam Medical College \& Research Foundation, Venjaramoodu, Trivandrum, Kerala, India

\section{ABSTRACT}

Objectives: The primary objective of this study was to determine if Early Clinical Exposure (ECE) and E-learning can be effective alternative methods of teaching anatomy for the first-year medical students. Secondary objectives were to determine (a) if there was gender bias with these methods and (b) if these methods influenced high, average or low achievers selectively.

Materials and Methods: Study was conducted in the department of anatomy with 150 first-year medical students participating in it. Students were randomly divided into three groups of 50 each. Six selected topics were taught to the three groups using ECE, e-learning and traditional lecture alternatively. After each session, a test was conducted using 20 objective questions to assess the learning outcome. Average score of the groups were analysed using Fisher one-way ANOVA or Welch test. M ultiple comparisons were done using post-hoc tests when the difference between the average scores was found to be significant. Gender difference in the scores for each method was noted. Learning outcome of high, average and low achievers with ECE and e-learning were compared. Results: Average total scores after ECE were comparable to lecture and superior to e-learning in five of the six sessions. E-learning, however, was not as effective as ECE in improving the test scores. Except for one group, where the boys outperformed the girls after e-learning, girls outperformed the boys in all the groups with all the three methods of instruction. ECE or e-learning did not influence high, average or low achievers selectively.

Conclusion: Based on the learning outcome, ECE can be an effective method to teach Anatomy in the described format. E-learning did not improve the test scores in the self-study format used in this study, but, 3D visualization can benefit the students when used as an adjunct to the traditional methods.

KEY WORDS: Early Clinical Exposure, E-learning, Blended Learning, learning outcome.

Address for Correspondence: Dr. M amata Chimmalgi, Professor, Department of Anatomy, Sree Gokulam M edical College \& Research Foundation, Venjaramoodu, Trivandrum - 695607 Telephone: 91-9387122769 / 9763887130 E-Mail: mamatachimmalgi@ gmail.com

\begin{tabular}{|c|c|c|}
\hline \multicolumn{3}{|c|}{ Access this Article online } \\
\hline \multirow{3}{*}{$\begin{array}{l}\text { Quick Response code } \\
\text { DOI: } 10.16965 / \text { ijar.2016.488 }\end{array}$} & \multicolumn{2}{|c|}{$\begin{array}{l}\text { Web site: International Journal of Anatomy and Research } \\
\text { ISSN 2321-4287 } \\
\text { www.ijmhr.org/ijar.htm }\end{array}$} \\
\hline & $\begin{array}{l}\text { Received: } 25 \text { Nov } 2016 \\
\text { Peer Review: } 27 \text { Nov } 2016\end{array}$ & $\begin{array}{l}\text { Accepted: } 04 \text { Jan } 2017 \\
\text { Published (0): } 31 \text { Jan } 2017\end{array}$ \\
\hline & Revised: None & Published (P): 31 Jan 2017 \\
\hline
\end{tabular}

\section{INTRODUCTION}

Design of the curriculum, burden of the syllabus, techniques of assessment and methods of instruction can all influence learners' enthusiasm and learning outcome. The methods of instruction become more effective if they are adapted to the learners' preferences and promote active participation.

Rigid pedagogical training followed in the first year often transforms the enthusiasm of the new medical students into disenchantment with the course, resulting in poor learning outcome. 
Hypothecating that, interesting and effective methods of instruction can singularly improve the learning outcomes, this study tries to look for alternative methods for teaching anatomy. While the importance of knowledge of anatomy in correctly diagnosing, and managing a patient cannot be overstressed, 'classroom teaching' often makes the first-year medical students feel that they are endlessly accumulating facts in anatomy without knowing the purpose. Introducing Early Clinical Exposure (ECE) during the first year can mitigate this problem. By integrating basic science knowledge with clinical science, ECE can contribute to better understanding of the relevance of anatomy and hence, greater satisfaction in medical education [1,2]. By providing an opportunity to actively interact and learn from patients and the clinicians, it can enrich their learning experience. By introducing the students to basic clinical skills, professionalism and student-patient relation, it can facilitate smooth transition into clinical training at the end of the year [3].

Students learn better as 'active participants' than 'passive recipients'. Traditional 'instructorcentred' methods therefore, need to evolve into newer 'student-centred' methods. E-learning is one such 'student-centred' method. Through interactive material in digital repository, immediate feedback and problem solving activities it can catalyse active participation $[4,5]$. Through computer enabled three-dimensional visualization, it can offset the limitations of verbal descriptions in teaching anatomy [6-10]. For the current tech-savvy generation, it can offer a platform to study through a media they enjoy. It gives them greater control over the content, time and pace of learning. For medical educators, it offers the benefit of freedom of time, shifting their role from mere 'content distributors' to 'facilitators of learning' [11].

The primary objective of the current study was to determine the effectiveness of ECE and E-learning as alternative methods for teaching anatomy for the first-year medical students by assessing their effect on the learning outcome. Secondary objectives were to determine (a) if there is gender bias with these methods and (b) if the methods influenced good or poor performers selectively.

\section{MATERIALS AND METHODS}

Study Design: Experimental study

Participants: Following Institutional Ethical Committee approval and informed consent, 150 firstyear medical students ( 62 males $\& 88$ females in 18 to 19 year age group) participated in this study. They were randomly divided into 3 groups of 50 after matching for group performance with a baseline comparison test.

Intervention: Six sessions were conducted with six selected topics (Table 1). The three groups were taught the topics using 'ECE', 'e-learning' and 'traditional lecture' alternatively so that, by the end of six sessions, every group was exposed twice to each method.

For ECE, the students were first briefly taught the relevant anatomy. They were then taken to the hospital where the clinician demonstrated the pre-selected clinical case or the procedure. E.g. For Cerebellopontine (CP) angle tumour, location of cerebellopontine angle, structures found in the region and their functions were briefly taught in the department of anatomy. In the hospital, the neurosurgeon described the case history and management, demonstrated the M RI images of the patient and the students then interviewed the patient. For the case of thyroid swelling, gross anatomy of thyroid gland was taught briefly, after which, the surgeon demonstrated a case of goitre, in surgery OPD, emphasizing on clinical anatomy.

For e-learning, students were asked to go through the study material uploaded in the computers at the institution's Central Library. The study material dealt with the relevant anatomy and clinical case details in the form of text document, references, PowerPoint presentations and URL links to the pre-selected videos on YouTube. Students were also free to explore the internet for any additional information. After initial instruction, there was no faculty guidance for the duration. Students studied the material by themselves and were free to discuss with other members in the group.

For the third group, acting as control, the same topic was taught in detail using traditional didactic lecture. Clinical case details were covered in the segment of applied importance. 
To prevent prior knowledge confounding the study results, students were given no prior information about the topic and the topic was not taught earlier. To minimise bias, all the three methods had equal learning time. A single teacher was involved in teaching anatomy and designing material for e-learning to maintain uniformity in style and quality. For each session, all the three groups were engaged on the same day and a test was conducted immediately after to prevent interchange of information between the groups.

Data Collection: After each session, a test was conducted using 20 objective questions to assess the learning outcome - ten were pertaining to gross anatomy and ten on clinical anatomy. Same teacher valued all the answers in all the six sessions.

Data Analysis: Scores for gross anatomy questions, clinical anatomy questions and total scores (Maximum marks: 10, $10 \& 20$ respectively) were separately noted. Following testing for null hypothesis, average scores for the three groups in each session were analysed using Fisher one-way ANOVA or unequal F-test (Welch test). If difference in the average scores was significant (level of significance set at 0.05), multiple pair-wise comparisons were done using post-hoc tests (Fisher's LSD or GamesHowell respectively). Gender bias for the method of instruction was assessed by comparing the average scores of the boys with those of the girls for each method.

Based upon their performance with traditional teaching, students were segregated as high, average and low achievers (with scores greater than $80 \%$, between $50-80 \%$ and less than $50 \%$ ). Out of the 150 students, 36 (24\%) were high achievers, 74 (49.33\%) average and 40(26.66\%) were low achievers. Whether ECE or e-learning selectively influenced the learning outcome of any of these performance tiers was analysed by comparing their group averages for each method.

\section{RESULTS}

First year medical students (62 males +88 females $=150$ ) were randomly divided into 3 groups of 50 after an initial baseline comparison test using $15 \mathrm{M}$ CQs (average scores of three groups being 8.64, 8.8 and 8.56).

Total Scores: In each session, the three groups were taught the same topic by using three different methods. After each session, a test was conducted on the topic for all the three groups with 20 objective questions (max. score 20). Average of Total Scores (ATS) for the three groups and 'p-value' (after one-way ANOVA or Welch test) in all the six sessions are given in Table 2.

Post-hoc test results: As the difference between the average scores (ATS) of the three groups was found to be statistically significant in all the six sessions (as shown by $p$-value in Table 2 ), multiple pair-wise comparisons were done using post-hoc tests.

Between ECE \& lecture, there was no significant difference between their average scores in the first five sessions, the two methods therefore, being comparable. In the sixth session, average score after lecture was better than ECE (p-value: 0.033).

Between E-learning \& lecture, average score after lecture was better than e-learning in four sessions (p-values: $0.001,0.017,0.032 \& \varangle 0.001$ in sessions II, III, V \& VI respectively) whereas in the remaining two, there was no significant difference between the two groups.

Between ECE \& E-learning, average scores after ECE was found to be significantly better than e-learning in five sessions ( $p$-values: 0.012 , $\varangle 0.001,0.028,0.001 \& 0.033$ in sessions I, II, III, $\mathrm{V} \& \mathrm{VI}$ respectively) while average score after e-learning was better than ECE in one session ( $p$-value $=0.018$ in session IV).

Gross Anatomy \& Clinical Anatomy Scores: In each test, 10 questions were pertaining to gross anatomy and 10 on clinical anatomy. Lectures are known to help scoring in gross anatomy while ECE with its emphasis on clinical anatomy, was expected to result in better understanding and better performance in clinical anatomy questions. Group-wise average scores for gross anatomy questions (AGS) and clinical anatomy questions (ACS) and p-value after one-way ANOVA or Welch tests are given in Table 3.

Post-hoc test results: Post-hoc tests were conducted for multiple pair-wise comparisons for those sessions that had significant difference between their average scores (as shown 
in Table 3 with $p$-value $\varangle$.05). For gross anatomy questions, the difference was significant in five of the six sessions (except session IV) whereas for the clinical anatomy questions, the difference between the average scores was significant in four of the six sessions (except sessions I \& VI).

Following multiple comparisons between the average scores for gross anatomy questions, scores after lecture was found to be better than e-learning in three sessions ( $p$-values: 0.029 in session III, $\varangle 0.001$ in II \& VI) and better than ECE in two sessions (p-values: $0.015 \& 0.040$ in sessions III \& VI). ECE was found to be significantly better than e-learning in four sessions ( $p$-values: $0.025,<0.001,0.003 \& 0.011$ in sessions I, II, V\& VI respectively). Following multiple comparisons between the average scores for clinical anatomy questions, ECE was found to be significantly better than e-learning in three sessions (p-values: $0.017, \varangle 0.001 \&$ 0.008 in sessions II, III $\& V$ respectively) while e-learning was better than both ECE and lecture in one session (p-value: $0.027 \& 0.001$ respectively in session IV). Elsewhere there was no significant difference.

In this batch, all the boys were regularly using laptops, tablets or smart phones, and were regularly surfing the internet and watching the YouTube videos. On the contrary, girls had sporadic to no access to internet. To determine if this ease of using the technology translated into better learning outcome with e-learning, performance of boys was compared with that of the girls. It was found that only the boys in group $A$ outperformed the girls after e-learning, whereas, the girls outperformed the boys in the other two groups. Girls also outperformed the boys in all the three groups after ECE and lecture in every session.

The students were divided into high, average and low achievers based upon their performance after the traditional teaching. When average total scores (ATS) of high, average \& low achievers after ECE and after e-learning were analyzed, it was found that there was no selective advantage to any performance tier. The discrimination between the three tiers was however, more marked after ECE (average scores for good, average and poor learners: 14.25, $12.52 \& 10.41$ respectively) than with e-learning $(12.76,12.23$ \& 10.23 respectively), making ECE a superior method. It was interesting to note that the high achievers failed to score markedly better than the average students with e-learning.

Table 1: Topics and group-wise methods of instruction.

\begin{tabular}{|c|c|c|c|c|}
\hline Session & Topic & Group A & Group B & Group C \\
\hline I & Intramuscular Injection & ECE & E-Learning & Lecture \\
\hline II & Lumbar Puncture & Lecture & ECE & E-Learning \\
\hline III & Thyroid Swelling & E-Learning & Lecture & ECE \\
\hline IV & CP Angle Tumour & ECE & E-Learning & Lecture \\
\hline V & Pituitary Tumour & Lecture & ECE & E-Learning \\
\hline VI & Spinal Cord Injury & E-Learning & Lecture & ECE \\
\hline
\end{tabular}

Table 2: Average Total Scores of Three Groups in Six Sessions \& p-values after ANOVA or Welch test.

\begin{tabular}{|c|c|c|c|c|}
\hline Session & ECE & E-Learning & Lecture & p-value \\
\hline & Avg, Score \pm SD (N) & Avg, Score \pm SD (N) & Avg. Score \pm SD (N) & \\
\hline I & $14.94 \pm 3.53(47)$ & $12.82 \pm 3.45(46)$ & $14.65 \pm 4.55(46)$ & $0.011^{*}$ \\
\hline II & $17.18 \pm 2.31(44)$ & $14.77 \pm 3.04(47)$ & $16.87 \pm 2.02(46)$ & $\varangle .001^{*}$ \\
\hline III & $10.46 \pm 3.48(49)$ & $8.87 \pm 3.46(43)$ & $10.60 \pm 3.29(49)$ & $0.032^{*}$ \\
\hline IV & $12.07 \pm 3.27(46)$ & $13.72 \pm 2.38(48)$ & $12.13 \pm 4.04(50)$ & $0.08^{*}$ \\
\hline V & $13.74 \pm 2.83(39)$ & $11.23 \pm 3.60(42)$ & $12.77 \pm 3.40(44)$ & $0.003^{*}$ \\
\hline VI & $11.67 \pm 3.31(49)$ & $10.29 \pm 2.87(49)$ & $13.06 \pm 3.37(49)$ & $<0.001^{*}$ \\
\hline
\end{tabular}

SD: Standard Deviation; N: Number of Students Participating; *: P-value significant

Table 3: Average Scores for Gross Anatomy \& Clinical Anatomy questions and $p$-Value after ANOVA / Welch Tests.

\begin{tabular}{|c|c|c|c|c|c|c|c|}
\hline & Session I & Session II & Session III & Session IV & Session V & Session VI \\
\hline & & Mean $\pm S D$ & Mean $\pm S D$ & Mean $\pm S D$ & Mean $\pm S D$ & Mean $\pm 5 D$ & Mean $\pm 5 D$ \\
\hline \multirow{4}{*}{$\begin{array}{l}\text { Gross } \\
\text { Anatomy } \\
\text { Questions }\end{array}$} & ECE & $7.48 \pm 1.73$ & $8.52 \pm 1.53$ & $3.85 \pm 1.86$ & $7.56 \pm 2.02$ & $7.02 \pm 1.88$ & $5.97 \pm 2.01$ \\
\hline & E-Learning & $6.53 \pm 1.74$ & $6.93 \pm 2.12$ & $3.93 \pm 2.13$ & $8.23 \pm 1.05$ & $5.70 \pm 2.25$ & $4.93 \pm 1.79$ \\
\hline & Lecture & $7.56 \pm 2.36$ & $8.44 \pm 1.31$ & $4.82 \pm 1.85$ & $8.05 \pm 2.27$ & $6.38 \pm 1.80$ & $6.81 \pm 2.16$ \\
\hline & p-value & $0.014^{*}$ & $<0.001 *$ & $0.027 *$ & 0.139 & $0.013 *$ & $<0.001 *$ \\
\hline \multirow{4}{*}{$\begin{array}{l}\text { Clinical } \\
\text { Anatomy } \\
\text { Questions }\end{array}$} & ECE & $7.44 \pm 2.33$ & $8.65 \pm 1.18$ & $6.60 \pm 2.07$ & $4.50 \pm 2.07$ & $6.71 \pm 1.68$ & $5.69 \pm 1.94$ \\
\hline & E-Learning & $6.28 \pm 2.62$ & $7.82 \pm 1.61$ & $4.94 \pm 1.83$ & $5.47 \pm 1.88$ & $5.52 \pm 1.87$ & $5.34 \pm 1.82$ \\
\hline & Lecture & $7.08 \pm 3.03$ & $8.40 \pm 1.37$ & $5.77 \pm 2.13$ & $4.08 \pm 2.35$ & $6.38 \pm 2.34$ & $6.24 \pm 1.70$ \\
\hline & p-value & 0.104 & $0.023^{*}$ & $0.001^{*}$ & $0.005^{*}$ & $0.023^{*}$ & $\overline{0.052}$ \\
\hline
\end{tabular}

$\mathrm{SD}=$ Standard Deviation; ${ }^{*}=$ P-value significant

\section{DISCUSSION}

Increasing number of medical schools across the globe are adopting ECE as a supplementary method. ECE advocates learning through application. Integrating knowledge of anatomy with real-life clinical scenarios results in more meaningful and experiential learning.

In the current study, ECE proved to be an effective method of teaching anatomy by positively influencing learning outcome as was shown by the test scores (Tables 2). Average total scores 
following ECE was significantly better than e-learning and comparable with lecture in five of the six sessions (Table 2 and post-hoc test results). Similar positive learning outcome was observed by Tayade et al, the scores in both MCQ tests and OSPE being significantly higher after ECE [3]. Duque et al observed that 78\% learners in one-week integrated exposure group scored $>75 \%$ marks in their final examinations [2]. Holden et al found only a mild impact on step 2 clinical knowledge scores following three weeks of clinical exposure in Neurology [12].

Although ECE facilitates better clinical correlation, it did not translate into better scores for clinical anatomy questions. Average scores for clinical anatomy questions after ECE were better than e-learning only in three sessions whereas it was not superior to lecture in any of the sessions (Table 2 and post-hoc test results).

Today's 'YouTube generation' is willing to integrate internet with education [13]. E-learning has positively influenced the learning outcomes in several studies. Chopra et al found that performance after teaching with computer assisted visual aid was significantly better [8]. Webb and Choi found that the performance of students in summative assessment was better after radiological anatomy e-learning solutions [10]. In the study conducted by Hallgren, the mean scores in both midterm and final exams of the students who had used the web-based instructional materials (Group 1) were significantly higher ( 28.5 with $p \varangle 0.001$ ) than the mean scores of those students (Groups $2 \& 3$ ) who did not use the material ( $26 \& 24$ in midterm and 26 for both groups in final exams) [14]. Hallgren opines that the study results might be confounded to some degree due to a selfselection bias of the method.

Post-test scores with MCQs in a study by Qayumi revealed that the 'computer and textbook' group and 'computer only' group scored better than the traditional group (46.4 and 45.0 marks vs. 34.7). A further sub-analysis demonstrated that the CAL package gave the most benefit to the low achievers while high achievers were less affected by the method of instruction [15]. In a randomized controlled trial by Nicholson, the group having access to the computer model of anatomy of internal ear scored significantly higher compared to the control group ( $83 \%$ vs. $65 \%, p<0.001$ ) [16].

$M$ any studies have also reported positive learning outcome with blended learning. In a large retrospective study done by Elizondo-Omana et al, students taught using traditional method had lower averages and lower percentage of passing than those taught using additional CAL (Computer Assisted Learning) [6]. They attribute it to students spending an additional 20 hours on the multimedia resources in the semester. Similar advantage with blended learning was noted by Silva et al $\&$ Pereira et al in their studies conducted in the departments of dermatology and anatomy $[17,18]$.

Contrary to the above cited studies, e-learning did not improve the test scores in this study. Except for session IV (Table 2), average total scores (ATS) or average scores for the gross and the clinical anatomy questions (AGS \& ACS) after e-learning were lesser than those for the other two methods.

Although one of the noted advantage of e-learning is control over pace of learning, time was restricted in this study to rule out method bias. There was also no faculty guidance for e-learning in this study. In India, students enter medical colleges immediately after their $12^{\text {th }}$ grade schooling, and, they are probably not ready for pure 'self-study' mode of e-learning adopted in this study. Restriction of time and absence of faculty guidance may have been the two vital factors that limited the benefits of e-learning in the current study. E-learning may therefore benefit the first-year students better if introduced in the blended form with unrestricted access to the digital content.

Even though the boys used the internet and various gadgets regularly, the familiarity with technology did not translate into better performance. Boys performed better than the girls after e-learning in only one group while girls outperformed the boys in the other two groups. They also performed better than the boys in all the three groups with ECE and lecture.

In this study, high, average or low achievers did not selectively benefit from ECE or e-learning. Although e-learning has been reported to benefit low achievers, we did not find similar 
result in our studies [15]. Instead, it was noted that high and average achievers performed similarly after e-learning, the method not being able to discriminate between the two groups. Discrimination between the high, average and low achievers was more marked with ECE.

\section{CONCLUSION}

ECE is found to be an effective alternative method to teach Anatomy in the described format. Learning outcome following ECE was comparable to that of lecture and superior to e-learning.

While e-learning provided opportunity to work with better visuals, animations and videos, it did not help learning outcome remarkably without faculty guidance and with restricted time.

Although boys in this study were more tech-savvy, their familiarity with technology did not translate into better performance with e-learning.

ECE and e-learning did not selectively help high or low achievers, although, discrimination between the groups was more marked with ECE.

\section{ACKNOWLEDGEM ENTS}

We are indebted to Dr. Jose P B, Consultant Neurosurgeon; Professor Priyadarshini, Professor Dayanand Babu, Professor Radhika, Dr. Sanjay Zakharia, other faculty members of Medicine \& Anaesthesia; Mrs. Ramani Pappachan, Nursing Superintendent; M r. Suresh \& staff, Central Library; Mr. Vishnu \& staff, IT department at Sree Gokulam Medical College and Research Foundation for their invaluable contribution. We are grateful to M rs. Manju L, Assistant Professor of Statistics for her contribution to statistical analysis. We thank the faculty members who have peer-reviewed this project. We also lovingly thank I M BBS students of 2015 batch for participating in this study enthusiastically.

\section{ABBREVIATIONS}

\footnotetext{
ECE - Early Clinical Exposure

ATS - Average of Total Score

AGS - Average of Gross Anatomy Questions Score

ACS - Average of Clinical Anatomy Questions Score

CAL - Computer Assisted Learning

Conflicts of Interests: None
}

\section{REFERENCES}

[1]. Johnson AK, Scott CS. Relationship between early clinical exposure \& first year students' attitudes towards medical education. Acad M ed. 1998;73(4):430432.

[2]. Duque G, Gold S\& Bergman H. Early Clinical Exposure to Geriatric Medicine in Second-Year Medical School Students-The McGill Experience. J of the Am Ger Soc. 2003;51(4):544-548.

[3]. Tayade MC, Bhimani N, Kulkarni NB, et al. The impact of early clinical exposure on first MBBS students. Int. J of Healthcare \& Biomed Res. 2014;2(4):176-181.

[4]. Boucher B, Hunter D \& Henry J. The effectiveness of computer-assisted instruction in teaching biomechanics of the temporomandibular joint. J of Phys Ther Educ. 1999;13:47.

[5]. Izet M. E-learning as new method of M edical Education. Acta Inform Med. 2008;16(2):102-117.

[6]. Elizondo-Omana RE, M orales-Gomez JA, Guzman SL, et al. Traditional Teaching Supported by Computer Assisted Learning for Macroscopic Anatomy. Anat Rec. 2004;278B:18-22.

[7]. Levinson AJ, Weaver B, Garside S, et al. Virtual reality and brain anatomy: A randomized trial of e-learning instructional designs. Med Educ. 2007;41:495-501.

[8]. Chopra J, Rani A, Rani A, et al. Traditional versus Computer Assisted Teaching of Human Osteology: A Randomized Control Trial Study. Ind J of Basic \& App Med Res. 2012:5(2):370-374.

[9]. Roth JA, Wilson TD, Sandig M. The development of a virtual 3D model of the renal corpuscle from serial histological sections for E-learning environments. Anat Sci Educ. 2015;8(6):574-583.

[10]. Webb AL, Choi S. Interactive radiological anatomy eLearning solution for first year medical students: Development, integration, and impact on learning. Anat Sci Educ. 2015;7(5):350-360.

[11]. Ruiz JG, M intzer MJ, Leipzig RM. The impact of elearning in medical education. Acad Med. 2006;81:207-212.

[12]. Holden KR, Cooper SL, Wong JG. Neuroscience curriculum changes and outcomes: medical university of South Carolina, 2006 to 2010. Neurologist. 2012;18(4):190-195.

[13]. Barry DS, Marzouk F, Chulak-oqlu K, et al. Anatomy education for the YouTube generation. Anat Sci Educ. 2016;9(1):90-96

[14]. Hallgren R. An interactive, web-based to ol for learning anatomic landmarks. Acad Med. 2002; 77(3):263265.

[15]. Qayumi A. Comparison of computer-assisted instruction (CAI) versus traditional textbook methods for training in abdominal examination (Japanese experience). Med Educ. 2004;38:1080-1088.

[16]. Nicholson D. Can virtual reality improve anatomy education? A randomized controlled study of a computer-generated three-dimensional anatomical ear model. Med Educ. 2006;40:1081-1087.

[17]. Silva CS, Souza MB, Silva FRS, et al. E-learning program for medical students in dermatology. Clinics (Sao Paulo). 2011;66(4):619-622.

[18]. Pereira JA, Pleguezuelos E, M erý' A, et al. Effectiveness of using blended learning strategies for teaching and learning human anatomy. Med Edu. 2007;41(2):189-195. 